\title{
PENGARUH DARI BRAND IMAGE DAN PRODUCT QUALITY MELALUI CUSTOMER SATISFACTION SEBAGAI VARIABEL MEDIATOR TERHADAP CUSTOMER LOYALTY
}

\author{
Eric Cantona \\ Program Studi Magister Manajemen Universitas Tarumanagara \\ ericcantona003@gmail.com
}

Masuk : 01-12-2020, revisi : 14-12-2020, diterima untuk diterbitkan : 15-12-2020

\begin{abstract}
The main key to the success of a business or company is none other than customer loyalty. So, the increase in customer loyalty needs to be considered. However, it is necessary to understand in advance what factors can affect the increase in customer loyalty. Customer loyalty can be influenced by several factors, including brand image, product quality, and customer satisfaction. In this research, we will discuss the influence of brand image and product quality on customer loyalty through customer satisfaction as a mediating variable for Shell fuel customers in Jakarta. Sampling using non-probability sampling with a purposive method to obtain appropriate characteristics for researchers. Respondents were 200 Shell fuel customers aged 17 - 50 years and over. The data analysis technique uses structural equation modeling. The results of this study indicate that brand image and product quality have a positive effect on customer loyalty. For the variable customer satisfaction, it can partially mediate brand image and product quality towards customer loyalty.
\end{abstract}

Keywords: Brand Image, Product Quality, Customer Satisfaction, Customer Loyalty

Abstrak: Kunci utama dari kesuksesan suatu bisnis atau perusahaan tidak lain adalah kesetiaan daripada pelanggan. Maka, peningkatan terhadap kesetiaan pelanggan perlu untuk diperhatikan. Namun, perlu dipahami terlebih dahulu faktor-faktor apa saja yang dapat mempengaruhi peningkatkan kesetiaan pelanggan tersebut. Customer loyalty dapat dipengaruhi oleh beberapa faktor antara lain seperti brand image, product quality, dan customer satisfaction. Dalam penelitian ini akan dibahas mengenai pengaruh pengaruh dari brand image dan product quality terhadap customer loyalty melalui customer satisfaction sebagai varibel mediasi pada konsumen BBM Merk Shell di Jakarta. Pengambilan sample menggunakan non-probability sampling dengan metode purposive untuk mendapatkan karakterisik yang sesuai bagi peneliti. Responden merupakan pelanggan BBM Merk Shell berusia 17 - 50 tahun ke atas sebanyak 200 responden. Teknik analisa data menggunakan pemodelan persamaan struktural. Hasil dari penelitian ini memperlihatkan bahwa brand image dan product quality berpengaruh secara positif terhadap customer loyalty. Untuk variabel customer satisfaction dapat memediasi secara parsial brand image dan product quality terhadap customer loyalty.

Kata kunci: Brand Image, Product Quality, Customer Satisfaction, Customer Loyalty

\section{PENDAHULUAN}

\section{Latar Belakang}

Tingginya kebutuhan akan BBM membuat banyak perusahaan berlomba-lomba untuk menyediakan kebutuhan tersebut sehingga meningkatkan persaingan antar perusahaan dalam memperebutkan kesetiaan dari para pelanggan.

Mempertahankan sikap loyalitas pelanggan bukanlah suatu yang mudah didapatkan ditengah ketatnya persaingan-persaingan bisnis modern kini. Langkah penting yang harus ditetapkan oleh perusahaan di benak konsumen adalah menciptakan imagezataupgambaran atau pandangan atau citra merk perusahaan yang baik. Menurut Wood (2000) dalam Ogba dan 
Tan (2009), bahwa brand image memiliki peran penting dalam memfasilitasi loyalitas pelanggan terhadap suatu produk. Untuk mendorong loyalitas pelanggan, maka kepuasan pelanggan terhadap produk perlu juga ditingkatkan. Menuruts selnes (1993) menyatakan bahwa kepuasan terhadap suatu brand dapat membawa konsumen menuju kesetiaan terhadap brand tersebut. Namun kepuasan pelanggan tersebut harus ditingkatkan dengan cara meningkatkan kualitas daripada produk tersebut. Menurut Cronin dan Taylor (1992) mengemukakan bahwa performa yang bagus dari produk memberikan dampak yang positif terhadap kepuasan dari konsumen .

\section{Kaitan antar Variabel}

Wood 2000 (dalam Ogba dan Tan 2009) di dalam bukunya dikatakan bahwa brand image bisa untuk memenuhi kebutuhan dan keinginan target market maka brand image dapat membantu meningkatkan loyalty konsumen terhadap brand tersebut.

Davies et al. (2003) mengatakan bahwa brand image dan satisfaction memiliki hubungan atau pengaruh yang postif. Pada penelitian sebelumnya Davies dan Chun (2002) menemukan bahwa brand image memiliki pengaruh tidak langsung terhadap customer loyalty melalui customer satisfaction.

Chumpitaz and Paparoidamis (2004) mengatakan hasil beberapa penelitian mendukung secara empiris bahwa kualitas produk merupakan anteseden dan memiliki hubungan positif dengan kepuasan konsumen secara keseluruhan. Artinya, menjaga kualitas produk yang tinggi akan memberikan kepuasan pelanggan dan juga meningkatkan loyalitas pelanggan.

Di dalam Yu dan Dean (2001) mengatakan bahwa hubungan antara customer satisfaction dan customer loyalty karena banyak penelitian sebelumnya telah mengkonfirmasi bahwa ada hubungan positif yang signifikan antara kedua variabel ini.

\section{Hipotesis}

H1: brand image dapat memberikan pengaruh positif terhadap customer satisfaction konsumen BBM merk Shell di Jakarta

H2: product quality dapat memberikan pengaruh positif terhadap customer satisfaction konsumen BBM merk Shell di Jakarta.

H3: brand image dapat memberikan pengaruh positif terhadap customer loyalty konsumen BBM merk Shell di Jakarta.

H4: product quality dapat memberikan pengaruh positif terhadap customer loyalty konsumen BBM merk Shell di Jakarta.

H5: customer satisfaction dapat memberikan pengaruh positif terhadap customer loyalty konsumen BBM merk Shell di Jakarta.

H6: customer satisfaction dapat memediasi brand image untuk memberikan pengaruh positif terhadap customer loyalty konsumen BBM merk Shell di Jakarta.

H7: customer satisfaction dapat memediasi product quality untuk memberikan pengaruh positif terhadap customer loyalty konsumen BBM merk Shell di Jakarta. ini.

Berdasarkan hipotesis , berikut model penelitian seperti terlampir pada gambar di bawah

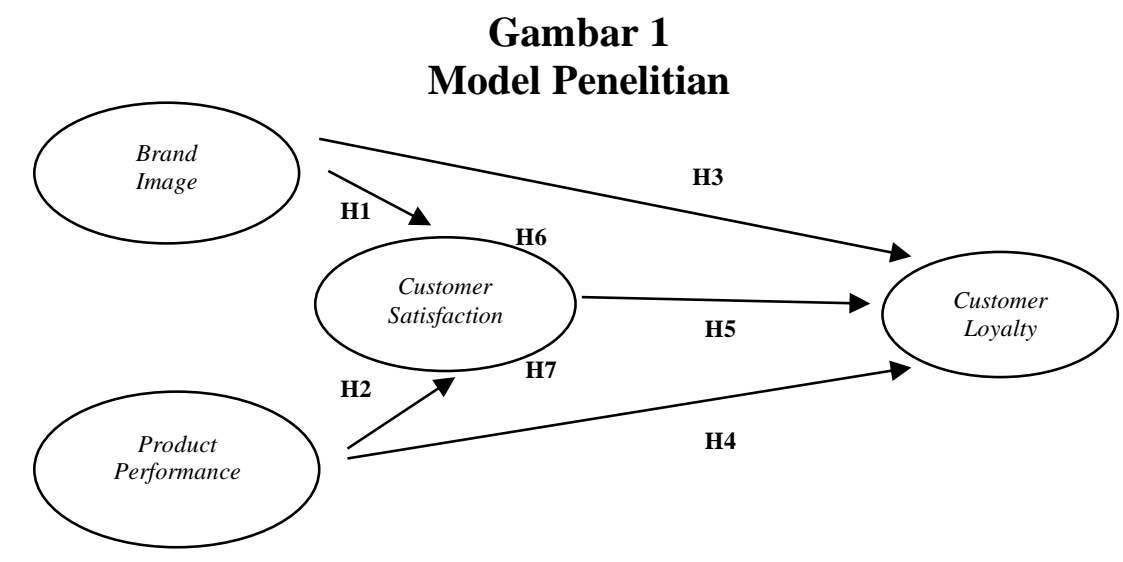




\section{METODE PENELITIAN}

Responden yang dapat terpilih dalam penelitian ini adalah pelanggan yang sudah pernah, sering atau bahkan selalu menggunakan BBM Merk Shell di Jakarta dengan rentang umur 1750 tahun keatas. Teknik sampling menggunakan non-probability sampling dengan metode purposive. Dari 330 kuisioner yang disebar secara online menggunakan google forms, data yang lolos sebanyak 200. Pengukuran jawaban responden menggunakan skala likert dengan rentang 1 (sangat tidak setuju) sampai dengan 5 (sangat setuju). Untuk teknik analisis data menggunakan structure equation modeling (SEM) yang diolah dalam aplikasi SmartPls 3 dengan tingkat signifikansi sebesar 5\%. Tabel 1 menunjukan instrument dari tiap variabel beserta sumbernya yang telah dilakukan analisis validitas dengan hasil analisis convergent validity yaitu nilai loading factor seluruh indikator seluruh variabel menunjukan hasil diatas 0,7 dan nilai AVE seluruh variabel lebih besar dari 0,5 (Henseler et al. 2009). Kemudian untuk analisis discriminant validity menunjukan nilai cross loading tiap indikator variabelnya lebih besar dari korelasi antar variabel lainnya dan analisis fornell-larcker menunjukan nilai akar kuadrat AVE lebih besar dari korelasi antar variabel lainnya sehingga seluruh instrumen dinyatakan valid (Henseler et al. 2009). Sementara untuk analisis reliabilitas didasarkan pada nilai cronbach's alpha dan composite reliability yang masing-masing hasilnya menunjukan nilai lebih dari 0,6 sehingga semua indikator dalam penelitian adalah reliabel (Maholtra, 2010).

\section{Tabel 1}

Pengukuran Variabel Penelitian

\begin{tabular}{|c|c|c|c|}
\hline No & Variabel & Item & sumber \\
\hline 1 & Brand Image & 6 & $\begin{array}{l}\text { Jumiati Sasmita \& Norazah Mohd Suki (2014), Ismail } \\
\text { \& Spinelli (2012) }\end{array}$ \\
\hline 2 & Customer Satisfaction & 3 & $\begin{array}{l}\text { Hur et al. (2014), Kaura et al. (2014), Lin dan Bennet } \\
\text { (2014) }\end{array}$ \\
\hline 3 & Product Quality & 3 & Kianpour \& Jusoh (2013), Chang \& Fong (2010) \\
\hline 4 & Customer Loyalty & 6 & Lin dan Bennet (2014), Yang \& Peterson (2004) \\
\hline
\end{tabular}

\section{HASIL DAN PEMBAHASAN}

Berdasarkan hasil pengujian koefisien determinasi diketahui nilai $R$ square adalah sebesar 0,670 yang berarti bahwa sebesar $67 \%$ dari variabel mediasi yaitu customer satisfaction dijelaskan oleh variabel-variabel yang terdapat dalam penelitian ini dan sisanya yaitu sebesar $33 \%(100 \%-67 \%)$ dijelaskan oleh variabel-variabel diluar penelitian ini dan sebesar 0,589 yang berarti bahwa sebesar 58,9\% dari variabel dependen yaitu customer loyalty dapat dijelaskan oleh variabel-variabel yang terdapat dalam penelitian ini dan sisanya yaitu sebesar 41,1\% (100\% - 58,9\%) dijelaskan oleh variabel-variabel di luar penelitian ini. Berdasarkan pendapat yang dikemukakan oleh Henseler et al. (2009), maka nilai $R$ square dalam penelitian ini tergolong kuat. Kemudian hasil pengujian dari $Q^{2}$ dalam penelitian ini adalah sebesar 0,381 dan $0,475\left(\mathrm{Q}^{2}>0\right)$ yang berarti bahwa konstruk variabel yang terdapat dalam penelitian ini relevan untuk mengukur model penelitian yang telah terbentuk sebelumnya dengan baik (Hair et al. 2011). Hasil pengujian disajikan pada tabel di bawah ini.

Berikut dipaparkan pada tabel hasil pengujian Hipotesis:

\section{Tabel 2}

Hasil Pengujian Hipotesis

\begin{tabular}{llll}
\hline Hipotesis & Coefficient & T-statistic \\
\hline H1 & Brand Image -> Customer Loyalty & 0.210 & 2.526 \\
\hline H2 & Brand Image -> Customer Satisfaction & 0.514 & 8.190 \\
\hline H3 & Customer Satisfaction -> Customer Loyalty & 0.300 & 3.238 \\
\hline H4 & Product Quality -> Customer Loyalty & 0.345 & 4.631 \\
\hline H5 & Product Quality -> Customer Satisfaction & 0.391 & 6.402 \\
\hline H6 & Brand Image -> Customer Satisfaction -> Customer Loyalty & 0.154 & 2.966 \\
\hline H7 & Product Quality -> Customer Satisfaction -> Customer Loyalty & 0.117 & 4.201 \\
\hline
\end{tabular}

$* \mathrm{p}<0,05 ; * * \mathrm{p}<0,01$ 
Berdasarkan Tabel 2. di atas dapat ditarik kesimpulan bahwa pengaruh variabel brand image terhadap customer loyalty, customer satisfaction terhadap customer loyalty, product quality terhadap customer loyalty, mediasi customer satisfaction terhadap brand image dan product quality kepada customer loyalty memiliki arah yang positif secara berturut-turut yaitu sebesar 0,210;0,300; 0,345 sebesar 0,154 dan 0,117. Kemudian untuk hasil seluruh hipotesis dapat terlihat bahwa semua hasil uji $t$-statistic lebih besar dari cut off value sebesar 1,96 sehingga dapat disimpulkan bahwa H1, H2, H3, H4, H5, H6 dan H7 tidak ditolak.

Hasil pengujian hipotesis pertama menunjukan brand image terbukti dapat memberikan pengaruh secara positif customer satisfaction customer bbm Merk Shell di Jakarta sehingga hipotesis $\mathrm{H} 1$ dinyatakan tidak ditolak. Hasil penelitian ini didukung dengan melihat dari hasil penelitian Ogba Tan (2009) yang menemukan hasil bahwa brand image memiliki pengaruh yang positif terhadap customer satisfaction. Selain itu penelitian sebelumnya lagi seperti Davies et al.(2003) dan Davies et al. (2002) juga menemukan hasil yang sama bahwa brand image memiliki pengaruh yang positif terhadap customer satisfaction.

Selanjutnya, hasil pengujian hipotesis $\mathrm{H} 2$ menemukan bahwa product quality terbukti dapat mempengaruhi secara positif customer satisfaction konsumen bbm merk Shell di Jakarta sehingga hipotesis $\mathrm{H} 2$ dinyatakan tidak ditolak. Hasil penelitian ini didukung menurut beberapa peneliti terdahulu seperti Cronin dan Taylor (1992); Mittal et al.(1998) dan juga Chumpitaz dan Paparoidamis (2004) yang menemukan bahwa kualitas produk memiliki hubungan yang juga positif terhadap customer satisfaction

Pada hipotesis ketiga yaitu brand image terbukti dapat mempengaruhi secara positif customer loyalty konsumen bbm merk Shell di Jakarta sehingga hipotesis $\mathrm{H} 3$ dinyatakan tidak ditolak. Hal tersebut sesuai dengan penelitian terdahulu yang dilakukan oleh Nyadzayo and Khajehzadeh (2016), Wood (2000), dan Ogba Tan (2009) yang semuanya mengemukakan dari penelitian yang mereka lakukan menghasilkan brand image dapat secara positif memiliki pengaruh terhadap customer loyalty.

Kemudian pada hipotesis keempat yaitu product quality terbukti dapat mempengaruihi secara positif customer loyalty konsumen bbm merk Shell di Jakarta sehingga hipotesis H4 dinyatakan tidak ditolak. Hasil ini didukung melalui penelitian sebelumnya dari Mittal et al (1998) dan juga Chumpitaz dan Paparoidamiz (2004) yang menemukan bahwa tingkat kualitas produk yang tinggi akan meningkatkan kesetiaan pelanggan terhadap produk dari brand tersebut. Produk yang dapat memenuhi kebutuhan dan harapan pelanggan secara kualitas dapat menjadi faktor yang sangat kuat untuk mendapatkan kesetiaan dari pelanggan.

Kemudian pada hipotesis kelima customer satisfaction terbukti dapat mempengaruihi secara positif customer loyalty konsumen bbm merk Shell di Jakarta sehingga hipotesis H5 dinyatakan tidak ditolak. Hal tesebut sesuai dengan penelitian yang dilakukan dahulu oleh Colgate dan Stewart (1998) yang menemukan bahwa customer satisfaction dapat memberikan pengaruh yang positif terhadap customer loyalty.

Kemudian pada hipotesis keenam dan ketujuh customer satisfaction terbukti dapat memediasi untuk memberikan pengaruh secara positif variabel brand image dan product quality terhadap customer loyalty konsumen bbm merk Shell di Jakarta sehingga hipotesis H6 dan $\mathrm{H} 7$ dinyatakan tidak ditolak. Hal ini dapat didukung melalui penelitian terdahulu Chang dan Fong (2010), Jahansashi et al. (2011) dan juga Yu,Chin,dan Hsiao (2012) yang menemukan bahwa brand image dapat dimediasi oleh customer satisfaction terhadap customer loyalty, demikian hal nya dengan product quality juga dapat dimediasi customer satisfaction terhadap customer loyalty.

\section{KESIMPULAN DAN SARAN}

Hasil penelitian menunjukan bahwa seluruh hipotesis tidak ditolak, dengan demikian, hasil penelitian juga memberikan saran agar perusahaan dapat menjaga kualitas produk karena hal tersebut ditemukan memiliki pengaruh yang sangat kuat terhadap loyalitas konsumen. 
Melakukan pengembangan serta inovasi pada produk akan semakin meningkatkan loyalitas dari konsumen. Penelitian ini secara teoritis dapat memberikan kontribusi terhadap penelitian terhadap perilaku konsumen dan pemasaran, secara khusus terhadap brand image, product quality, customer satisfaction, dan customer loyalty.

Bagi penelitian selanjutnya, dihimbau untuk menggunakan variabel lain yang dapat mempengaruhi loyalitas konsumen seperti customer experience, brand love, brand personality, word of mouth, customer perceived value, service quality, service convenience, price and fairness, dan juga memperluas cakupan penelitian. Diharapkan pada penelitian selanjutnya dapat dikembangkan dalam konteks produk atau mungkin jasa pada industri yang berbeda.

\section{REFERENSI}

AutoExpose. (2016, October). Pilih Pertamax apa Shell Super? Cek Perbandingannya AutoExpose. Retrieved from https://www.autoexpose.org/2016/10/mana-pilihan-andapertamax-atau-shell.html

Chang, N. J., \& Fong, C. M. (2010). Green product quality, green corporate image, green customer satisfaction, and green customer loyalty. African journal of business management, 4(13), 2836-2844.

Chumpitaz, R., \& Paparoidamis, N. G. (2004). Service quality and marketing performance in business-to-business markets: exploring the mediating role of client satisfaction. Managing Service Quality: An International Journal.

Cronin Jr, J. J., \& Taylor, S. A. (1992). Measuring service quality: a reexamination and extension. Journal of marketing, 56(3), 55-68.

Davies, G., \& Chun, R. (2002). Gaps between the internal and external perceptions of the corporate brand. Corporate reputation review, 5(2-3), 144-158.

Davies, G., Chun, R., Da Silva, R. V., \& Roper, S. (2003). Corporate reputation and competitiveness. Psychology Press.

Hair, J., Ringle, C., \& Sarstedt, M. (2011). PLS-SEM: Indeed A Silver Bullet. The Journal of Marketing Theory and Practice, 19(2), 139-151.

Henseler, J., Ringle, C., \& Sinkovics, R. (2009). The Use of Partial Least Square Path Modeling in International Marketing. Advances in International Marketing, 20, 277-319

Hur, W. M., Moon, T. W., \& Jung, Y. S. (2015). Customer response to employee emotional labor: the structural relationship between emotional labor, job satisfaction, and customer satisfaction. Journal of Services Marketing.

Ismail, A. R., \& Spinelli, G. (2012). Effects of brand love, personality and image on word of mouth. Journal of Fashion Marketing and Management: An International Journal.

Jahanshahi, A. A., Gashti, M. A. H., Mirdamadi, S. A., Nawaser, K., \& Khaksar, S. M. S. (2011). Study the effects of customer service and product quality on customer satisfaction and loyalty. International Journal of Humanities and Social Science, 1(7), 253-260.

Kaura, V., Prasad, C. S. D., \& Sharma, S. (2015). Service quality, service convenience, price and fairness, customer loyalty, and the mediating role of customer satisfaction. International Journal of Bank Marketing.

Kianpour, K., Jusoh, A., \& Asghari, M. (2014). Environmentally friendly as a new dimension of product quality. International Journal of Quality \& Reliability Management.

Lin, Z., \& Bennett, D. (2014). Examining retail customer experience and the moderation effect of loyalty programmes. International Journal of Retail \& Distribution Management.

Malhotra, N. K. (2010). Marketing Research: An Applied Orientation. Pearson Pretince Hall

Mittal, B., \& Lassar, W. M. (1998). Why do customers switch? The dynamics of satisfaction versus loyalty. Journal of services marketing.

Nyadzayo, M. W., \& Khajehzadeh, S. (2016). The antecedents of customer loyalty: A moderated mediation model of customer relationship management quality and brand image. Journal of Retailing and Consumer Services, 30, 262-270. 
Ogba, I. E., \& Tan, Z. (2009). Exploring the impact of brand image on customer loyalty and commitment in China. Journal of Technology Management in China.

Selnes, F. (1993). An examination of the effect of product performance on brand reputation, satisfaction and loyalty. European Journal of marketing, 27(9), 19-35.

Shell Indonesia. (n.d.). Aktivitas kami. Retrieved from https://www.shell.co.id/in_id/tentangkami/what-we-do.html

Shell Indonesia. (n.d.). Shell Regular. Retrieved from https://www.shell.co.id/in_id/pengendara-bermotor/bahan-bakar-shell/shellregular.htmhttps://www.shell.co.id/in_id/tentang-kami/the-shell-brand.html

Suki, J. S. N. M., \& Sasmita, J. (2015). Young consumers' insights on brand equity: Effects of brand association, brand loyalty, brand awareness, and brand image. International Journal of Retail \& Distribution Management, 43(3), 276-292.

Tu, Y. T., \& Chang, H. C. (2012). Corporate brand image and customer satisfaction on loyalty: An empirical study of Starbucks coffee in Taiwan. Journal of Social and Development Sciences, 3(1), 24-32.

Wood, L. (2000). Brands and brand equity: definition and management. Management decision.

Yang, Z., \& Peterson, R. T. (2004). Customer perceived value, satisfaction, and loyalty: The role of switching costs. Psychology \& marketing, 21(10), 799-822. 